Research Paper

\title{
Comparison of Endoscopic Submucosal Dissection Application on Mucosal Tumor and Subepithelial Tumor in stomach
}

\author{
Wen-Hung Hsu',2, Tzung-Shiun Wu ${ }^{3}$, Meng-Shu Hsieh ${ }^{1}$, Yu-Min Kung, Yao-Kuang Wang1,2, Jeng-Yih Wu ${ }^{1,2}$, \\ Fang-Jung $\mathrm{Yu}^{1,2}$, Chao-Hung Kuo ${ }^{2,4}$, Yu-Chung Su ${ }^{1,2}$, Jaw-Yuan Wang ${ }^{5}$, Deng-Chyang Wu ${ }^{1,2}$, Huang-Ming \\ $\mathrm{Hu}^{2,3}$ \\ 1. Division of Gastroenterology, Department of Internal Medicine, Kaohsiung Medical University Hospital, Kaohsiung, Taiwan \\ 2. Department of Medicine, College of Medicine, Kaohsiung Medical University, Kaohsiung, Taiwan. \\ 3. Department of Internal Medicine, Kaohsiung Municipal Ta-Tung Hospital, Kaohsiung, Taiwan. \\ 4. Department of Internal Medicine, Kaohsiung Municipal Siaogang Hospital, Kaohsiung, Taiwan. \\ 5. Division of Colorectal Surgery, Department of Surgery, Kaohsiung Medical University Hospital, Kaohsiung, Taiwan. \\ $\triangle$ Corresponding author: Huang-Ming Hu, MD, MS. Department of Internal Medicine, Kaohsiung Municipal Ta-Tung Hospital and Kaohsiung Medical University, \\ Kaohsiung, Taiwan. 100 Tz-You 1st road, Kaohsiung 807, Taiwan. Tel: +886-7-3121101-7451; Fax: +886-7-3135612 E-mail: kevinhu837@gmail.com.
}

(C) The author(s). This is an open access article distributed under the terms of the Creative Commons Attribution License (https://creativecommons.org/licenses/by/4.0/). See http://ivyspring.com/terms for full terms and conditions.

Received: 2020.05.01; Accepted: 2020.10.04; Published: 2021.01.01

\begin{abstract}
Background: Endoscopic submucosal dissection is minimal invasive endoscopic procedure to deal with gastric tumor. Initially, it was developed to resect mucosal neoplasm since 2000 and extended its application to submucosal tumor in the following years. Although the basic ESD skills are similar in gastric mucosal tumor and subepithelial tumor, the success rate, complication may be different between the two types of gastric tumor resection. This retrospective study is conducted to analyze the ESD procedure in gastric mucosal tumor and subepithelial tumor.

Methods: From 2007 to 2016, we reviewed all patients who underwent endoscopic submucosal dissection for gastric mucosal tumor and subepithelial tumor in Kaohsiung Medical University Hospital.

Results: Totally, 35 patients with gastric subepithelial tumor and 41 patients with gastric mucosal tumor received endoscopic submucosal dissection are enrolled. Among 35 patients with subepithelial tumor, 32 (91.4\%) patients achieved curative treatment. 1 patient received emergent operation and 2 patients received salvage operation to complete tumor resection. 8 patients $(22.9 \%)$ occurred perforation and no delay bleeding was found. Among 41 patients with mucosal neoplasm, 30 (71.4\%) patients achieved curative treatment. 2 patients received emergent operation and 9 patients received salvage operation to complete tumor resection. 9 patients (21.9\%) occurred complication, 6 patients occurred delay bleeding and 3 patients had perforation.

Conclusions: Comparing ESD between gastric mucosal tumor and subepithelial tumor, ESD had similar efficiency in curative treatment. However, ESD in subepethelial tumor encountered higher perforation and lesser delay bleeding.
\end{abstract}

Key words: endoscopic submucosal dissection (ESD), gastric subepithelial tumor (SET)

\section{Introduction}

Gastric tumor can be divided into epithelial tumor and subepithelial tumor based on its origin. $90 \%$ of gastric tumors including adenoma and adenocarcinoma are originated from epithelium [1]. If these epithelial tumors are diagnosed as limited to mucosa, endoscopic mucosa resection skills such as EMR and ESD could be reasonable choices to complete tumor local resection with organ preservation. In particular,
ESD has a higher en-block resection rate which makes it as a treatment for early gastric cancer [2, 3]. Although subepithelial tumor (SET) responds to $10 \%$ of gastric tumor, it still has potential malignant and indication of resection exited as an important issue to get pathologic examination and tumor resection [4].

ESD was initially developed since 1990 for mucosal cancer resection, and recent reports proved 
its curative resection rate reached 95\% [5]. In the past decade, this skill has also extended its application to subepithelial tumor resection [6, 7]. Until now, the indication of ESD for gastric SET was controversial and efficacy was different within previous reports. This retrospective study is design to analyze, compare the efficacy and complication of ESD between epithelial tumor and subepithelial tumor in single center.

\section{Material and Methods}

\section{Patients}

In Kaohsiung Medical University Hospital, we started ESD for gastric tumor treatment since 2007 and extended its application to SET resection since 2011. We retrospectively analyzed all of the cases of mucosal tumor and subepethelial tumor received ESD between January 2007 and December 2016. We identified 76 patients who underwent ESD for gastric tumor, 35 patients SET and 41 mucosal neoplasms respectively. The indications for gastric mucosal tumor ESD were: differentiated intramucosal cancer without ulceration, irrespective of the tumor size; differentiated intramucosal cancer with ulceration, size less than $30 \mathrm{~mm}$; differentiated cancer with minute submucosal invasion, size less than $30 \mathrm{~mm}$; undifferentiated intramucosal cancer without ulceration, size less than $20 \mathrm{~mm}$. The indications for gastric subepithelial tumor ESD were EUS or CT proved intraluminal growing of gastric subepthelial tumor.

\section{Endoscopic Submucosal dissection}

\section{Anesthesia}

All ESD procedure performed under general anesthesia via endotracheal intubation for air-way protection and vital signs were monitored closely during the procedure.

\section{Instruments}

Both tip-covered type knife (IT knife, KD-610L; Olympus) and tip-uncovered type (precut needle knife, CD-1L, Dualknife KD-650L, Olympus) were used in endoscopic submucosal dissection. Coagrasper (FD-410LR, Olympus) was used for intraoperation bleeding. Electrosurgical unit used ESG-100 (Olympus). A single channel endoscope (GIF-Q260, GIF-Q260J, Olympus) with hood was used.

\section{ESD procedure}

Marking was done around $2 \mathrm{~mm}$ outside the margin of target lesion with needle knife or Dual knife (Force coagulation-1, $20 \mathrm{~W}$ ). An initial cut was made with a tip-uncovered knife outside the marking after injecting a glycerol solution of epinephrine $(1: 100,000)$ and diluted indigo carmine into the submucosal layer. Injection volume varied according to lesion size, and injections were repeated during the procedure as needed. Mucosal circumferential cutting was performed with IT knife (pulse slow cutting $25 \mathrm{~W}$ ). Submucosal dissection was performed with IT knife or tip-uncovered type knife (force coagulation-2, 40 W). Intra-operation bleeding was managed with coagrasper (soft coagulation, $70 \mathrm{~W}$ ).

\section{Histopathological evaluation}

The resected mucosal tumor were flattened and fixed at their periphery by thin needles onto a plate of wood, then fixed in a formalin solution. The margins of the tumor, depth, histological type, size, macroscopic appearance and lymphovascular infiltration were assessed pathologically with hematoxylin-eosin staining. Histological classification was microscopically carried out according to the revised Vienna classification of gastrointestinal epithelial neoplasia.

The removed SET were analyzed with hematoxylin-eosin staning and immunohistochemical staining with CD117, CD-34, smooth muscle actin (SMA) and S-100.

\section{Strategy of follow up}

Follow-up endoscopy was performed 6, and 12 months after treatment to assess the completeness of resection in the first year; thereafter, it was examined annually to diagnose local recurrence. Biopsy was repeated for histopathologic evaluation when tumor recurrence was suspected.

\section{Statistical analysis}

The statistical analyses are performed using SPSS software (SPSS, Version 20; Chicago, IL, United States). Quantitative data are tabulated as mean \pm SD. Prevalence or positive rates of categorical variables are expressed as a percentage (\%). Parametric data are compared using the Student's t-test, while non-parametric data are compared using Chi-Square test or Mann-Whitney $\mathrm{U}$ test. A value of $\mathrm{P}<0.05$ is considered to be statistically significant in all the analysis.

\section{Results}

\section{Characteristics of patients with SET and mucosal tumor (Table 1)}

Totally, 35 patient with SET and 41 patients with mucosal tumor received gastric ESD. The location of SET were more often over upper body and mucosal were tend to locate over low body such as antrum/ anglaris $(\mathrm{P}<0.001)$. Among the 35 patients with SET, 
29 patients received $7.5 \mathrm{Mz}$ or $12-\mathrm{Mz}$ endosopic ultrasound (EUS) to evaluate the size and location of SET. It showed $27 \mathrm{SET}$ origined from $4^{\text {th }}$ layer (muscle propria) and two were origined from $3^{\text {rd }}$ layer (submucosal layer). The other 6 SET cases received computer tomography scan before ESD. All of SETs were introlutmial growthing. The mean procedure time of SET ESD was 76.1 minutes and shorter than 111.6 minutes of mucosal ESD $(\mathrm{P}=0.012)$. The curative treatment rate were 32/35 (91\%), 30/41 (73\%) in SETs and epithelial tumor respectively. In the case series of ESD for SET and mucosal tumor also revealed the procedure time of SET ESD were shorter than mucosal tumor ESD (Figure 1).

Table 1. Character of gastric ESD

\begin{tabular}{|c|c|c|c|}
\hline & $\begin{array}{l}\text { Gastric subepithelial } \\
\text { tumor }(n=35)\end{array}$ & $\begin{array}{l}\text { Gastric mucosa } \\
\text { tumor }(n=41)\end{array}$ & $P$ value \\
\hline $\operatorname{Sex}(M / F)$ & $12 / 23$ & $26 / 15$ & 0.011 \\
\hline Age & $62.1(40 \sim 84)$ & $69.1(29 \sim 90)$ & 0.018 \\
\hline \multicolumn{4}{|l|}{ Location } \\
\hline Upper & 19 & 2 & \multirow[t]{3}{*}{0.000} \\
\hline Middle & 12 & 1 & \\
\hline Lower & 4 & 38 & \\
\hline Procedure time & $76.1(20 \sim 260)$ & $111.6(45 \sim 322)$ & 0.012 \\
\hline Curative treatment & 32 & 30 & 0.072 \\
\hline \multicolumn{4}{|l|}{ Complication } \\
\hline Delay bleeding & 0 & 6 & \multirow[t]{2}{*}{0.016} \\
\hline Perforation & 8 & 3 & \\
\hline \multicolumn{4}{|l|}{ Surgical intervention } \\
\hline Emergent op. & 1 & 2 & \multirow[t]{2}{*}{0.110} \\
\hline Salvage op. & 2 & 9 & \\
\hline Hospitalization days & $8.4(3 \sim 22)$ & $10.6(5 \sim 22)$ & 0.041 \\
\hline
\end{tabular}

\section{Complicated and simplified ESD in SET and mucosal tumor}

Because of intra-operation perforation, delay bleeding and surgical intervention (including emergent operation and salvage operation for noncurative ESD) would associated with prolong hospital days and complication, all of these situations that occurred would defined as complicated ESD.

In the subepithelial tumor (Table 2), 9 patients $(25.7 \%)$ had encountered complicated ESD. 8 patients occurred intra-operation perforation and 1 patient had salvage operation due to incomplete tumor resection. Among these perforation cases, 2 patients were associated incomplete tumor resection. One received emergent operation for tumor resection with partial gastrectomy, another one use hemoclip to close perforation and received elective surgery for tumor resection 2 days later. The other 6 patients of perforation received conservative medical treatment with endoscopic hemoclip closure and subsequent antibiotics treatment of $5 \sim 7$ days without surgical intervention. Tumor size bigger than $3 \mathrm{~cm}$ wound associated with higher rate of complicated ESD $(\mathrm{P}=0.027)$ for not only gastric perforation, but also esophagus laceration as specimen extraction from natural orifice (Figure 2). Compared with leiomyoma, GIST wound also associated with higher rate of complicated ESD $(\mathrm{P}=0.023)$. In the mucosal tumor group (Table 3), 17 patients $(41.5 \%)$ had encountered complicated ESD. 6 patients occurred delay bleeding, 3 patients had perforation, 9 patients had elective surgery for curative treatment for gastric cancer. Among the 3 cases of perforation, 2 cases received emergent operation for tumor resection and 1 case used endoscopic hemoclip closed perforation and recovery after conservative treatment. Histology with undifferentiated adenocarcinoma would associated with higher rate of complicated ESD $(\mathrm{P}=0.03)$.

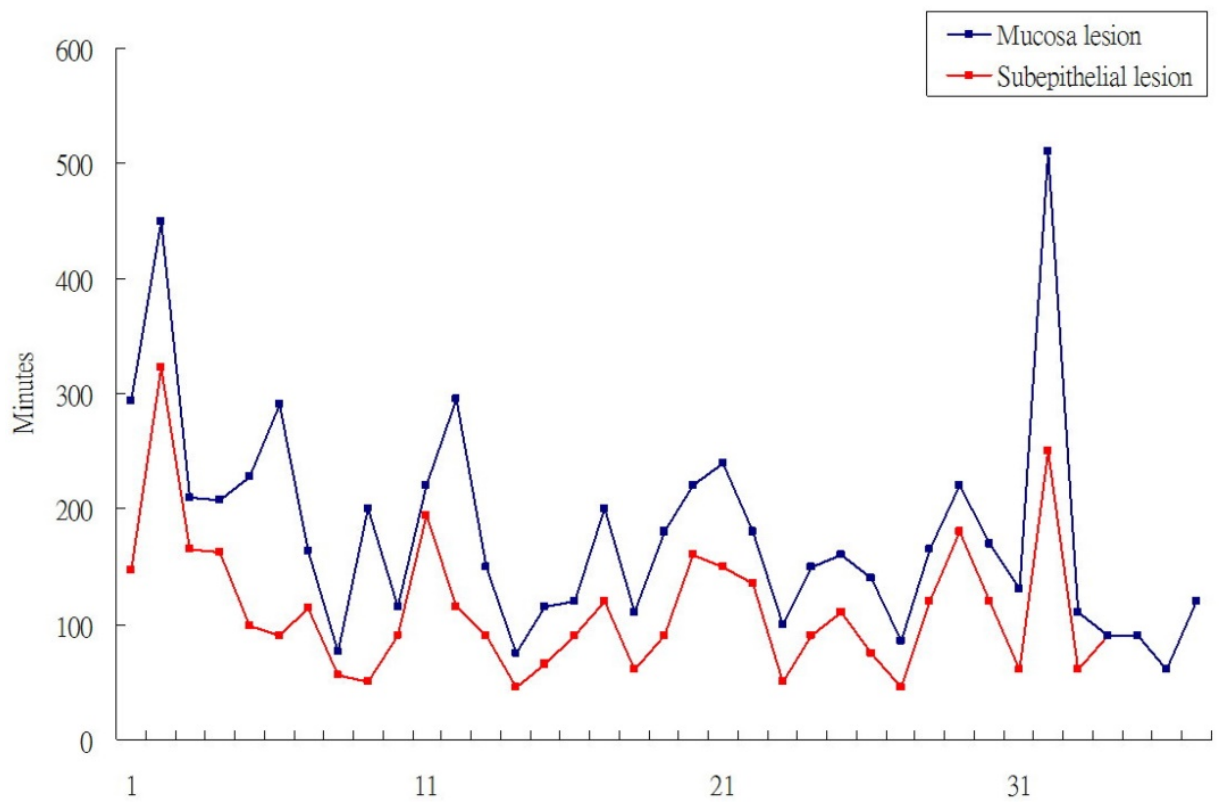

Figure 1. Procedure time of epithethial tumor ESD and SET ESD. 

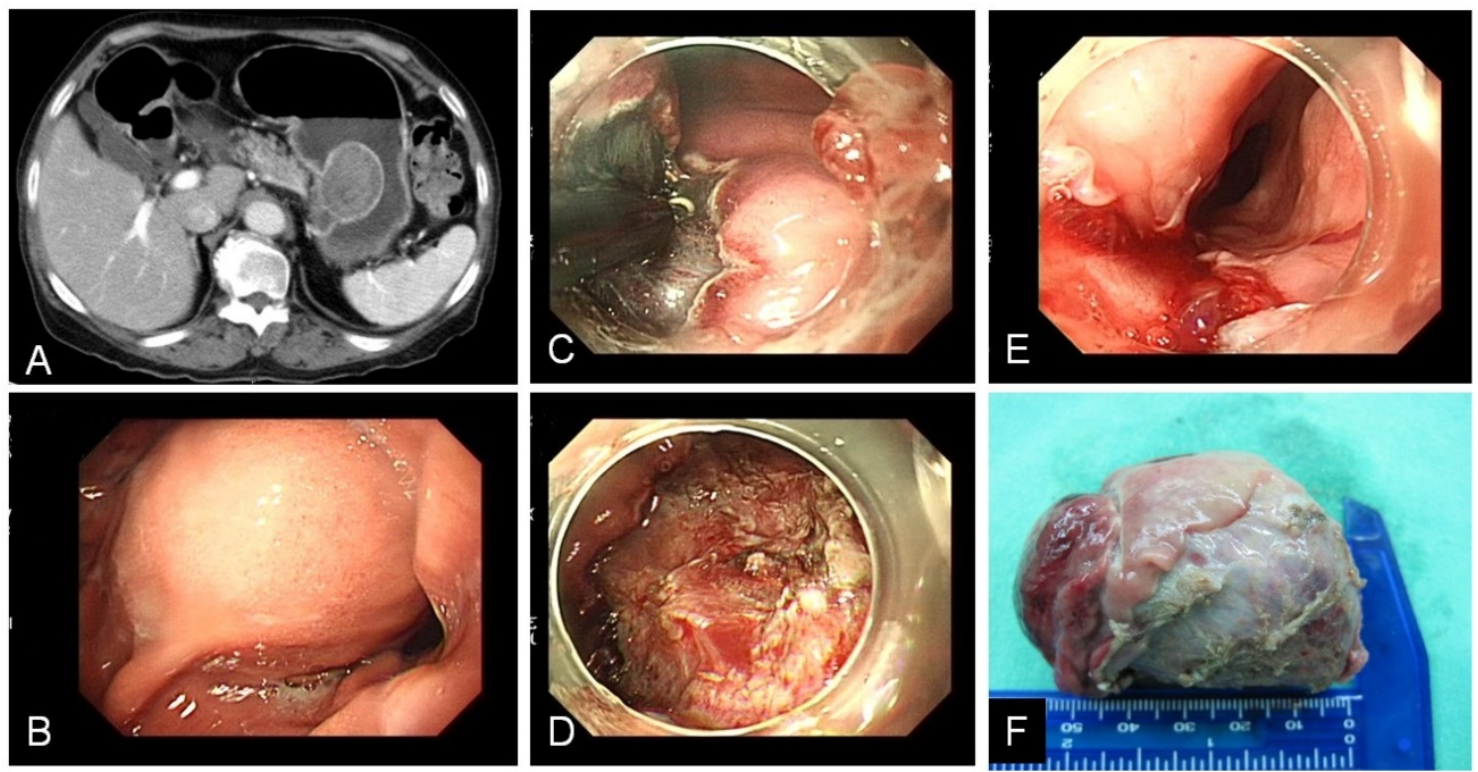

Figure 2. A.B. CT and endoscopy showed gastric subepithelial tumor with size more than $3 \mathrm{~cm}$ over stomach upper body. C. ESD performed with IT-knife. D. Post ESD gastric ulcer. E. Upper esophagus laceration after specimen extracted out. F. Specimen.

Table 2. Comparison of complicated ESD/simplified ESD in gastric subepithelial tumor

\begin{tabular}{llll}
\hline & $\begin{array}{l}\text { Complicated ESD } \\
(\mathrm{n}=9)\end{array}$ & $\begin{array}{l}\text { Simplified ESD } \\
(\mathrm{n}=26)\end{array}$ & $P$ value \\
\hline Mean age & $64.3(40 \sim 81)$ & $61.3(40 \sim 84)$ & 0.505 \\
Gender (M/F) & $4 / 5$ & $8 / 18$ & 0.685 \\
Location & & & \\
Upper & 4 & 15 & 0.748 \\
Middle & 4 & 8 & \\
Lower & 1 & 3 & 0.027 \\
Size & & & \\
$>3 \mathrm{~cm}$ & 4 & 2 & 0.023 \\
$<3 \mathrm{~cm}$ & 5 & 24 & \\
Pathologic diagnosis & & & \\
GIST & 6 & 10 & \\
Leiomyoma & 0 & 13 & $3^{* *}$ \\
Other & $3^{*}$ &
\end{tabular}

Complicated ESD: perforation, delay bleeding, surgical intervention, Simplified ESD: curative ESD without complication.

*Adenocarcinoma 1, Neuroendocrine tumor 1, schwannoma 1;

**Ectopic pancreas 1, Neuroendocrine tumor 1, lymphangioma 1.

\section{Pathologic diagnosis of SET}

Among 35 SET, 33 patients (94.3\%) got adequate specimen for pathologic diagnosis of SET. 2 patients received operation to achieve pathologic diagnosis because of intra-procedure perforation and incomplete tumor resection. Most SETs were pathologically diagnosed as GIST $(45.7 \%)$ and leiomyoma $(37.1 \%)$. Other few SETs were neuroendocrine tumor, schwannoma, lymphangioma, ectopic pancrease $(5.7 \%, 2.8 \%, 2.8 \%, 2.8 \%$, respectively) (Table 4$)$.

\section{Discussion}

The prevalence of subepithelial gastric lesions was around $0.36 \%$ during routine endoscopy examination [8]. The differential diagnosis of SETs is not easy and includes non-neoplastic lesions, benign neoplasms, and, potentially, overtly malignant tumors. EUS is a useful tool for evaluation of SETs, but the presumptive EUS and pathological diagnosis matched in only 77-82.9\% of cases [9-11]. According to the position of the American Gastrointestinal Association Institute, patients with SETs $<3 \mathrm{~cm}$ can be followed up with periodic endoscopy or endoscopic ultrasonography (EUS) [12]. However, this approach involves issues related to patient compliance, costeffectiveness, and the risk associated with repeated endoscopic procedures. Therefore, histologic examination is necessary for accurate diagnosis. However, standard endoscopic forceps biopsies, jumbo biopsy and EUS-assisted sampling had reported disappointing result $[13,14]$.

Table 3. Comparison of complicated ESD/simplified ESD in gastric mucosa tumor

\begin{tabular}{llll}
\hline & $\begin{array}{l}\text { Complicated ESD } \\
(\mathrm{n}=17)\end{array}$ & $\begin{array}{l}\text { Simplified ESD } \\
(\mathrm{n}=24)\end{array}$ & P value \\
\hline Mean age & $70.3(45 \sim 90)$ & $68.3(29 \sim 88)$ & 0.657 \\
$\begin{array}{l}\text { Gender (M/F) } \\
\text { Location }\end{array}$ & $7 / 10$ & $19 / 5$ & 0.013 \\
Upper & 1 & & 0.464 \\
Middle & 1 & 1 & \\
Lower & 15 & 0 & \\
Size & & 23 & 0.094 \\
$>3$ cm & 13 & & \\
$\leq 3$ cm & 5 & 22 & 0.03 \\
Pathologic diagnosis & & 2 & \\
Differentiated & 11 & 24 & \\
Undiffirrentiated & 6 & 0 & \\
Complicated ESD: perforation, delay bleeding, surgical intervention, Simplified \\
ESD: curative ESD without complication.
\end{tabular}


Table 4. Pathologic character of subepithelial tumor $(n=35)$

\begin{tabular}{ll}
\hline & Case number $(\%)$ \\
\hline Gastrointestinal stromal tumor & \\
High-risk GIST & $5(14.3)$ \\
Low-risk GIST & $11(31.4)$ \\
Leiomyoma & $13(37.1)$ \\
Neuroendocrine tumor & $2(5.7)$ \\
Schwannoma & $1(2.8)$ \\
Lymphangioma & $1(2.8)$ \\
Ectopic pancrease & $1(2.8)$ \\
Other & $1(2.8)$ \\
\hline
\end{tabular}

ESD was innovative method in management of superficial gastrointestinal neoplasm and this technique has become popular in Japan since 2000 [15], it has been established as a standard therapeutic method for early gastric epithelial tumor. It may also be considered as a promising minimal invasive technology to treat gastric SETs [16-18].

Overall, the efficiency of ESD in epithelial tumor achieved $95 \%$ of curative rate with similar to surgical gastrectomy in previous report [19]. However, the present study only had curative rate of $70 \%$ in epithelial tumor. It may be related to that the initial epithelial tumor ESD were still within the learning period. Besides, some epithelial cases were undifferential adenocarcinoma (extended criteria of gastric ESD) and it would be more challenge to endoscopic submucosal dissection [20, 21]. Our hosptial is low volume hospital of ESD and only 76 ESD procedures were done in past 10 years. The experience of ESD would also influence the success rate and management of adverse event. On the other hand, the curative rate of SET ESD was $90 \%$ in the present study. It is not only for treatment purposes but also to make an accurate histological diagnosis.

Although the basic skills of ESD in dealing of mucosal tumor and SET were similar, the target is different in the course of ESD respectively. In epithelial tumor ESD, the dissection is away from muscle layer, but SET ESD has to deal with muscle layer. Most gastric SET origin from 4th layer (muscular propria layer) of gastric wall and submucosa dissection course would have large chance to contact the muscular layer. In present study, the perforation rate was obviously higher in SETs group than epithelial tumor. Oppositely, delay bleeding was higher in epithelial tumor than SET. This may be because most epithelial tumor were larger than $3 \mathrm{~cm}$ and associated with bigger post ESD artificial gastric ulcer. In the past decade, several novel endoscopic devices promise endoscopic full thickness resection. Over-the-scope clip was showed safety and efficacy in resection SET less than $10 \mathrm{~mm}$ $[22,23]$. Endoscopic suturing system (such as Apollo Overstitch) had applied in larger gastrointestinal wall defect closure and varied endosurgery procedure [24]. All of these advance equiement make gastric SET endoscopic section easier.

Report from Choi et al hinted that trainee would need to perform $20 \pm 40$ procedures to be able to use the technique safely and effectively [25]. Others report that experience of at least 30 cases is required for a beginner to gain early proficiency in this technique [26]. Another study by N. Kakushima et al was not able to demonstrate an optimal number of cases required to gain adequate experience [27]. Besides, it suggested that a beginner could begin to treat lesions in the lower part of the stomach to gain the technique of ESD. There was no report to discussing the SET ESD learning cure. The present study showed SET ESD had shorter the procedure time and higher curative rate. So, the learning cure may be similar to epithelial ESD. However, higher potential of perforation was the important issue in the beginning of SET ESD.

Some limitations exist in the present study. First, this is single center, single operator study. There was no experience ESD operator to supervise the ESD procedure and the learning cure of ESD procedure may be different with other institute. Second, the case numbers were small both in epithelial tumor and SET and most of these case were in initial period of developing ESD. The success rate tends to lower and complication tends to higher. Third, there were not including other endoscopic skill such full-layer resection or STER in the management of SET in this study. Untill now, there still have debates in the endoscopic resection of gastrointestinal stromal tumor eventhough even though advance of endoscopic resection modality [6, 28]. Further large scale studies and loger follow-up would warrant clarifying the rule of endoscopic resection in gastric GIST.

\section{Conclusion}

ESD is considered to be a therapeutic technique with a higher radical cure for upper gastrointestine neoplasm treatment, but it may result in a risk of complication. This highly technical procedure needs a high level of expertise and experience to correctly carry out the submucosal dissection and to promptly control any procedure-related complications. Compare with mucosal tumor ESD, SET ESD had high curative rate with proper histology diagnosis. However, higher perforation rate would be important issue in dealing SET ESD in the initial cases. Endoscopic closing skill would be essential for gastric SET ESD. 


\section{Acknowledgements}

This study was supported by Kaohsiung Medical University, Taiwan (KMU-Q103026), Kaohsiung Medical University Hospital, Taiwan (KMUH1033M02) and Kaohsiung Municipal Ta-Tung Hospital, Taiwan (KMTTH-107-031).

\section{Competing Interests}

The authors have declared that no competing interest exists.

\section{References}

1. Crew KD, Neugut AI. Epidemiology of gastric cancer. World J Gastroenterol. 2006; 12: 354-62.

2. Chung IK, Lee JH, Lee SH, Kim SJ, Cho JY, Cho WY, et al. Therapeutic outcomes in 1000 cases of endoscopic submucosal dissection for early gastric neoplasms: Korean ESD Study Group multicenter study. Gastrointest Endosc. 2009; 69: 1228-35.

3. Fujishiro M, Yoshida S, Matsuda R, Narita A, Yamashita H, Seto Y. Updated evidence on endoscopic resection of early gastric cancer from Japan. Gastric Cancer. 2017; 20: 39-44.

4. Kim SY, Kim KO. Management of gastric subepithelial tumors: The role of endoscopy. World J Gastrointest Endosc. 2016; 8: 418-24.

5. Toyonaga T, Man-i M, East JE, Nishino E, Ono W, Hirooka T, et al. 1,635 Endoscopic submucosal dissection cases in the esophagus, stomach, and colorectum: complication rates and long-term outcomes. Surg Endosc. 2013; 27: $1000-8$

6. Kim HH. Endoscopic treatment for gastrointestinal stromal tumor: Advantages and hurdles. World J Gastrointest Endosc. 2015; 7: 192-205.

7. He G, Wang J, Chen B, Xing X, Chen J, He Y, et al. Feasibility of endoscopic submucosal dissection for upper gastrointestinal submucosal tumors treatment and value of endoscopic ultrasonography in pre-operation assess and post-operation follow-up: a prospective study of 224 cases in a single medical center. Surg Endosc. 2016; 30: 4206-13.

8. Hedenbro JL, Ekelund M, Wetterberg P. Endoscopic diagnosis of submucosal gastric lesions. The results after routine endoscopy. Surg Endosc. 1991; 5: 20-3.

9. Polkowski M, Butruk E. Submucosal lesions. Gastrointest Endosc Clin N Am. 2005; 15: 33-54, viii.

10. Ji F, Wang ZW, Wang LJ, Ning JW, Xu GQ. Clinicopathological characteristics of gastrointestinal mesenchymal tumors and diagnostic value of endoscopic ultrasonography. J Gastroenterol Hepatol. 2008; 23: e318-24.

11. Rosch T, Kapfer B, Will U, Baronius W, Strobel M, Lorenz R, et al. Accuracy of endoscopic ultrasonography in upper gastrointestinal submucosal lesions: a prospective multicenter study. Scand J Gastroenterol. 2002; 37: 856-62.

12. Hwang JH, Rulyak SD, Kimmey MB. American Gastroenterological Association Institute technical review on the management of gastric subepithelial masses. Gastroenterology. 2006; 130: 2217-28.

13. Fletcher CD, Berman JJ, Corless C, Gorstein F, Lasota J, Longley BJ, et al. Diagnosis of gastrointestinal stromal tumors: A consensus approach. Hum Pathol. 2002; 33: 459-65.

14. Ito $\mathrm{H}$, Inoue $\mathrm{H}$, Ryozawa $\mathrm{S}$, Ikeda $\mathrm{H}$, Odaka $\mathrm{N}$, Eleftheriadis $\mathrm{N}$, et al. Fine-needle aspiration biopsy and endoscopic ultrasound for pretreatment pathological diagnosis of gastric gastrointestinal stromal tumors. Gastroenterol Res Pract. 2012: 139083

15. Ono H, Kondo H, Gotoda T, Shirao K, Yamaguchi H, Saito D, et al. Endoscopic mucosal resection for treatment of early gastric cancer. Gut. 2001; 48: 225-9.

16. An W, Sun PB, Gao J, Jiang F, Liu F, Chen J, et al. Endoscopic submucosal dissection for gastric gastrointestinal stromal tumors: a retrospective cohort study. Surg Endosc. 2017; 31: 4522-31.

17. Meng FS, Zhang ZH, Hong YY, Li DJ, Lin JQ, Chen X, et al. Comparison of endoscopic submucosal dissection and surgery for the treatment of gastric submucosal tumors originating from the muscularis propria layer: a single-center study (with video). Surg Endosc. 2016; 30: 5099-107.

18. Chu YY, Lien JM, Tsai MH, Chiu CT, Chen TC, Yang KC, et al. Modified endoscopic submucosal dissection with enucleation for treatment of gastric subepithelial tumors originating from the muscularis propria layer. BMC Gastroenterol. 2012; 12: 124

19. Yokoe M, Hata J, Takada T, Strasberg SM, Asbun HJ, Wakabayashi G, et al. Tokyo Guidelines 2018: diagnostic criteria and severity grading of acute cholecystitis (with videos). J Hepatobiliary Pancreat Sci. 2018; 25: 41-54.

20. Gotoda T, Yanagisawa A, Sasako M, Ono H, Nakanishi Y, Shimoda T, et al. Incidence of lymph node metastasis from early gastric cancer: estimation with a large number of cases at two large centers. Gastric Cancer. 2000; 3: 219-25.

21. Gotoda T. Endoscopic resection of early gastric cancer. Gastric Cancer. 2007; 10: $1-11$

22. Kobara H, Mori H, Fujihara S, Nishiyama N, Ayaki M, Oryu M, et al. A novel strategy for complete duodenal endoscopic submucosal dissection involving prophylactic defect closure with over-the-scope clips. Endoscopy. 2016; 48 Suppl 1: E190-1.

23. Kappelle WFW, Backes Y, Valk GD, Moons LMG, Vleggaar FP. Endoscopic full-thickness resection of gastric and duodenal subepithelial lesions using a new, flat-based over-the-scope clip. Surg Endosc. 2018; 32: 2839-46.

24. Stavropoulos SN, Modayil R, Friedel D. Current applications of endoscopic suturing. World J Gastrointest Endosc. 2015; 7: 777-89.

25. Choi IJ, Kim CG, Chang HJ, Kim SG, Kook MC, Bae JM. The learning curve for EMR with circumferential mucosal incision in treating intramucosal gastric neoplasm. Gastrointest Endosc. 2005; 62: 860-5.

26. Gotoda T, Friedland S, Hamanaka H, Soetikno R. A learning curve for advanced endoscopic resection. Gastrointest Endosc. 2005; 62: 866-7.

27. Kakushima N, Fujishiro M, Kodashima S, Muraki Y, Tateishi A, Omata M. A learning curve for endoscopic submucosal dissection of gastric epithelial neoplasms. Endoscopy. 2006; 38: 991-5.

28. Joo MK, Park JJ, Kim H, Koh JS, Lee BJ, Chun HJ, et al. Endoscopic versus surgical resection of GI stromal tumors in the upper GI tract. Gastrointest Endosc. 2016; 83: 318-26. 